\title{
Um Caso Clínico de Sarcoidose Cutânea, Pulmonar, Esplénica e Neurosarcoidose
}

\section{A Clinical Case of Cutaneous, Pulmonar, Splenic and Neurologic Sarcoidosis}

Bela Machado ${ }^{1}$, Ana Rita Matos², Teresa Mendonça ${ }^{3}$, Fátima Farinha ${ }^{3}$

Autor Correspondente/Corresponding Author:

Bela Machado [bela.belinha@gmail.com] Rua da Falésia n 19, 9125-032 Caniço, Madeira, Portugal ORCID iD: 0000-0002-6775-2341

\begin{abstract}
RESUMO
A sarcoidose é uma doença granulomatosa que pode afetar qualquer órgão de etiologia desconhecida. Apresentamos o caso de um homem, de 49 anos, com antecedentes pessoais de um episódio de eritema nodoso. $\bigcirc$ estudo imagiológico do tórax mostrou múltiplas adenopatias mediastínicas e justa-hilares bilaterais, apesar de não apresentar queixas respiratórias. O lavado broncoalveolar revelou uma relação de células CD4/CD8 de 9,98 e o estudo analítico revelou uma enzima conversora da angiotensina elevada, sem outros achados. $\bigcirc$ doente iniciou corticoterapia verificando-se uma melhoria das manifestações cutâneas. Após dois anos, apresenta-se na consulta de Medicina Interna com queixas de emagrecimento, anorexia, fadiga, hipoacusia, síndrome vertiginosa e hipostesia dorsal em banda. Este caso mostra o envolvimento multissistémico da sarcoidose, tendo como ponto de partida para o seu diagnóstico uma manifestação cutânea e realça a importância da vigilância e do tratamento destes doentes a fim de um controlo atempado da doença.
\end{abstract}

PALAVRAS-CHAVE: Doenças da Pele; Doenças do Sistema Nervoso Central; Sarcoidose; Sarcoidose Pulmonar

1. Interna de Formação Específica de Medicina Interna, Hospital Central do Funchal, Funchal, Madeira, Portugal. 2. Interna de Formação Específica de Medicina Interna, Hospital de Braga, Braga, Portugal. 3. Assistente Hospitalar Graduada de Medicina Interna, Centro Hospitalar do Porto, Hospital Santo António, Porto, Portugal.

Recebido/Received: 18/01/2020 - Aceite/Accepted: 05/03/2020 - Publicado/Published: 31/03/2020

• Autor (es) (ou seu (s) empregador (es)) 2019. Reutilização permitida de acordo com CC BY-NC. Nenhuma reutilização comercial. ${ }^{\circledR}$ Author(s) (or their employer(s)) 2019. Re-use permitted under CC BY-NC. No commercial re-use. 


\begin{abstract}
Sarcoidosis is a granulomatous disorder that can affect any organ of unknown etiology. Presented is the study case of a male patient, 49-years of age with history of erythema nodosum. Upon performance of a thorax imagiological study it was visible multiple bilateral hilar and mediastinal adenopathy although there were no respiratory complaints. A bronchoalveolar lavage revealed a ratio of cells CD4/CD8 of 9.98 and the analytical study revealed a high angiotensin converting enzyme, without other findings. The patient started corticotherapy which improved his cutaneous manifestations. After two years, the patient presents to Internal medicine consultation complaining of weight loss, anorexia, fatigue, hypoacusic, episodic verdigo and spine hypoesthesia. This case shows the multisystemic involvement of sarcoidosis having as a starting point for its diagnosis a cutaneous manifestation and highlights the importance of monitoring and treating these patients for a timely and effective control of the disease.
\end{abstract}

KEYWORDS: Central Nervous System Diseases; Sarcoidosis; Sarcoidosis, Pulmonary

\section{INTRODUÇÃO}

A sarcoidose é uma doença granulomatosa multissistémica caracterizada pela acumulação de granulomas não caseosos nos órgãos afetados. Mais frequentemente, afeta os pulmões, os gânglios linfáticos e a pele, porém qualquer órgão pode ser afetado. ${ }^{1,2}$ A etiologia permanece desconhecida, no entanto, a presença de granulomas inflamatórios sugere que a doença resulte de uma resposta imune celular exagerada a um ou mais antigénios. ${ }^{1}$ Agentes ocupacionais, tais como o berílio e o alumínio, ou agentes infecciosos tais como o Mycobacterium tuberculosis são possíveis agentes etiológicos. ${ }^{1,3}$ Afeta sobretudo adultos jovens, com idades entre os 20 e os 60 anos, sendo mais comum em indivíduos de raça negra. ${ }^{4}$ As manifestações e a gravidade da própria doença variam também com a raça, as formas mais severas foram descritas em indivíduos de raça negra, enquanto que os caucasianos apresentam-se na sua maioria assintomáticos e com formas crónicas da doença. ${ }^{5}$

Dado a panóplia de manifestações possíveis desta doença é necessária uma investigação exaustiva destes doentes, bem como a exclusão de outras doenças granulomatosas. $^{2}$

\section{CASO CLÍNICO}

Apresenta-se o caso clínico, de um indivíduo do sexo masculino, de 49 anos, de raça caucasiana, construtor civil com antecedentes pessoais de um episódio de lesões nodulares, dolorosas, de tonalidade lilás, no terço distal da face anterior de ambos os membros inferiores em 2015. Por suspeita de eritema nodoso e para estudo da situação clínica foi pedido uma radiografia do tórax póstero-anterior que revelou ingurgitamento hilar bilateral (Fig. 1).
Para melhor caracterização, o doente realizou uma tomografia computorizada do tórax que confirmou múltiplas adenopatias mediastínicas e justa-hilares bilaterais compatíveis com sarcoidose pulmonar em estadio I (Fig. 2).

De seguida, o doente realizou broncofibroscopia com lavado broncoalveolar negativo para células malignas e com uma relação CD4/CD8 9,98. O doente iniciou terapêutica com prednisolona $40 \mathrm{mg} / \mathrm{dia}$ com melhoria das queixas cutâneas e sem outra sintomatologia. $\mathrm{O}$ doente não manteve seguimento na consulta de Pneumologia e passados dois anos, recorre à consulta de Medicina Interna por queixas de perda ponderal e fadiga. Sem achados de relevo ao exame objetivo. Foi pedida nova tomografia computorizada torácica e abdominal (Fig. 3) que revelou um extenso padrão micronodular, destruição perilinfática predominantemente nos lobos superiores e adenopatias em todos os compartimentos mediastíni-

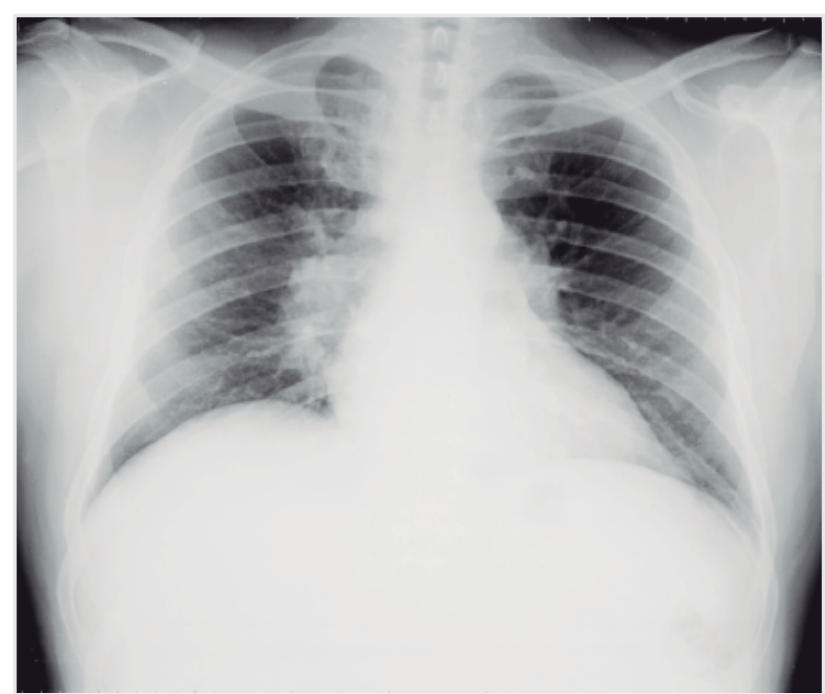

FIGURA 1. Radiografia do tórax póstero-anterior mostrando um reforço da trama broncovascular, predomínio peri-hilar, mais evidente à direita, com esboço de formação nodular. 

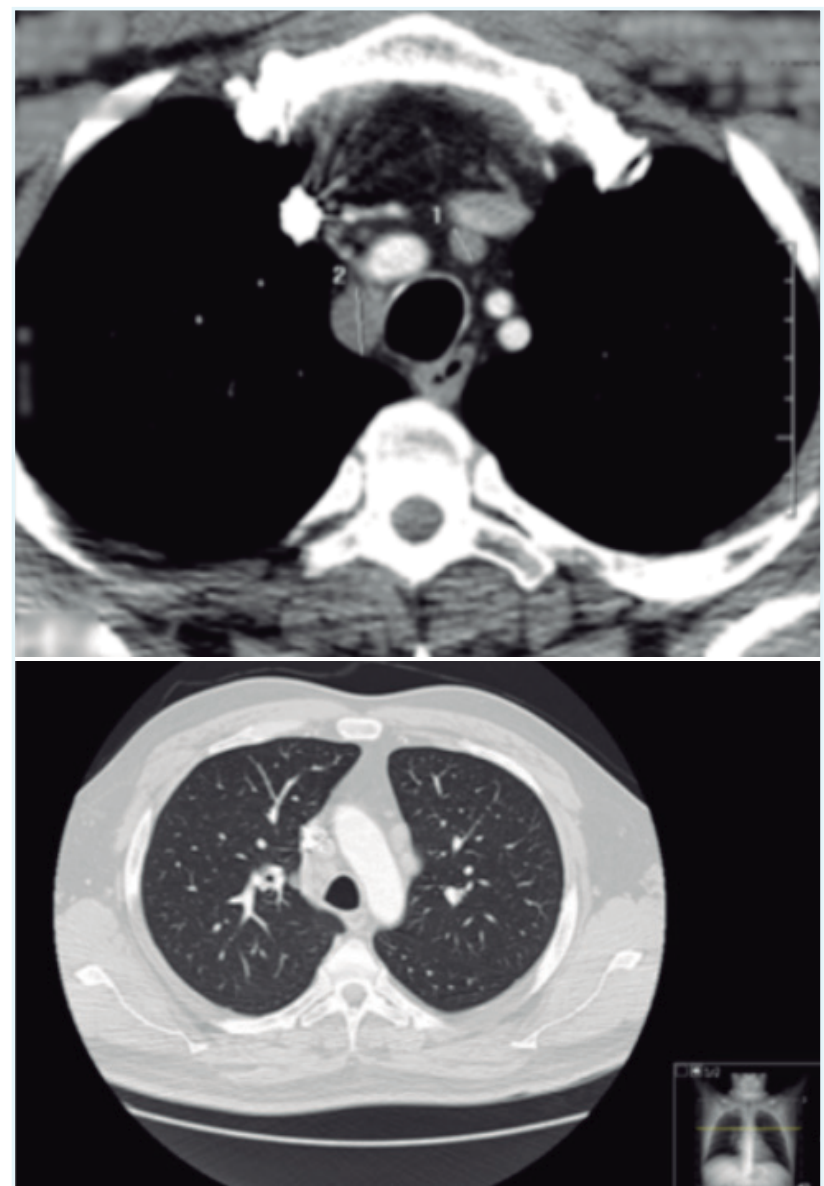

FIGURA 2. Tomografia computorizada do tórax mostrando múltiplas adenopatias mediastínicas e justa-hilares (assinaladas pelos algarismos 1 e 2) e sem envolvimento parenquimatoso pulmonar sendo a favor de um estadio I.

cos. Apresentava também um baço micronodular, adenomegálias nas cadeias lombo-aórticas, pericelíacas e inguinais.

Iniciou novamente tratamento com prednisolona. O doente referia também uma diminuição da acuidade auditiva que se traduziu em hipoacusia neurossensorial direita, uma síndrome vertiginosa e uma hipostesia em banda ao nível de D10, sugestivo de mielopatia dorsal parcial sem tradução imagiológica. $\bigcirc$ estudo analítico do doente apresentava uma enzima conversora de angiotensina de $164 \mathrm{U} / \mathrm{L}$ (valor de referência 8-76 U/L) que normalizou com a corticoterapia e sem outras alterações. As serologias e o estudo imunológico foram negativos. O eletrocardiograma, o Holter e o ecocardiograma não revelaram alterações sugestivas de envolvimento cardíaco. Dada a sintomatologia compatível com neurosarcoidose e a necessidade contínua de corticoterapia, o doente iniciou terapêutica com metotrexato. Verificou-se uma melhoria clínica e após 6 meses de terapêutica apresenta-se assintomático até à data.
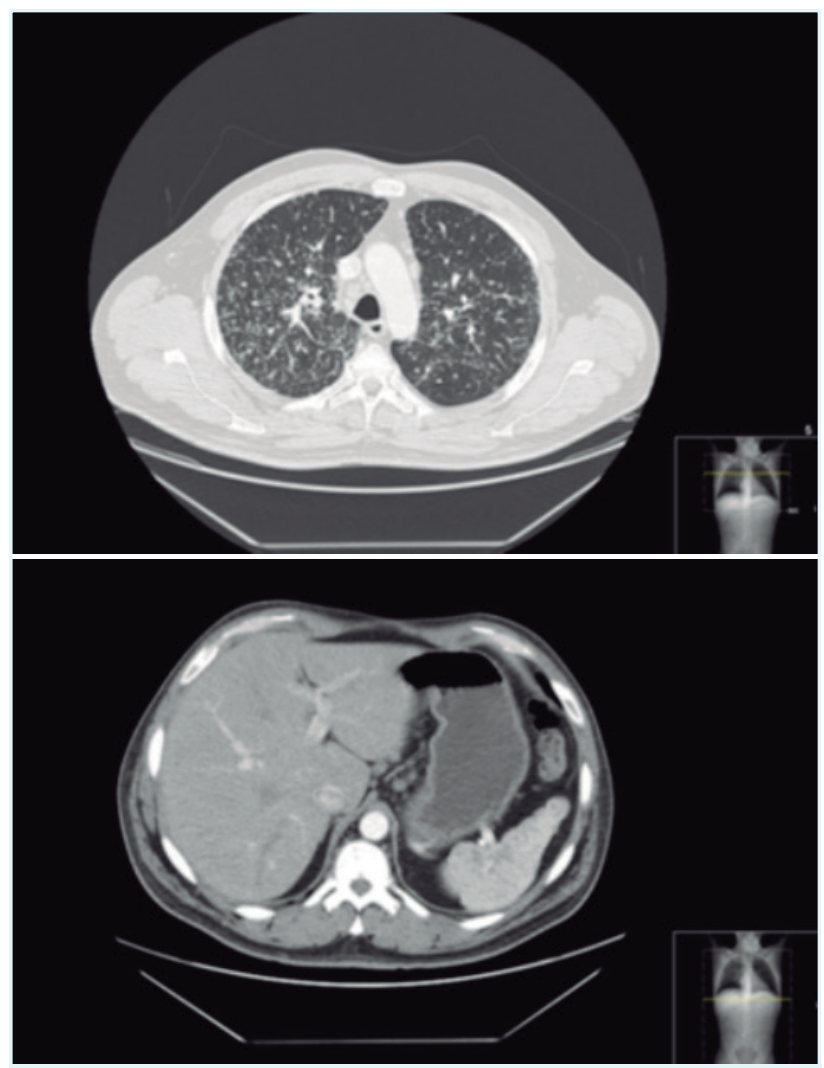

FIGURA 3. Tomografia toraco-abdomino-pélvica realizada após 2 anos de diagnóstico mostrando um extenso envolvimento do parênquima pulmonar e adenopatias (estadio II) e envolvimento esplénico (baço com aspeto micronodular).

\section{DISCUSSÃO}

A sarcoidose é uma doença granulomatosa que pode afetar qualquer órgão. $\bigcirc$ início da doença pode ser agudo ou insidioso e caracteriza-se por um vasto leque de sintomatologia. ${ }^{4,5}$ Pode apresentar-se com sintomas constitucionais tais como fadiga, anorexia, perda de peso, artralgias e sintomas respiratórios como tosse, dispneia e toracalgia. A fadiga é um sintoma comum que ocorre em cerca de $80 \%$ dos doentes com sarcoidose e o nível de fadiga parece estar associado com a presença de manifestações extrapulmonares. ${ }^{6}$ A sarcoidose mais frequentemente envolve os pulmões, em cerca de $90 \%$ dos doentes, com achados imagiológicos que variam desde a presença de adenopatias hilares bilaterais, a opacidades reticulares sobretudo nos lobos superiores e em estadios mais avançados, a fibrose com distorção da arquitetura pulmonar. $\bigcirc$ envolvimento pulmonar pode ser classificado em estadios radiográficos: estadio I definido pela presença de adenopatias hilares bilaterais e pode ser o primeiro achado da doença, tal como verificado neste caso clínico. $O$ estadio II consiste na presença de adenopatias hilares bilaterais e opacidades reticulares 
sobretudo nos lobos superiores. Estes doentes apresentam fadiga e perda de peso tal como sucedeu com este doente. $O$ estadio III e IV corresponde a estadios mais avançados da doença com a formação de bronquiectasias e de cavitações. ${ }^{7}$ O envolvimento cutâneo ocorre em 25\% dos doentes com sarcoidose e geralmente é um achado precoce. Tal como verificado neste caso, em que o eritema nodoso foi a manifestação inicial e a pista para o estudo e consequente diagnóstico. $O$ eritema nodoso é uma paniculite, caracterizada por nódulos dolorosos que são mais comuns na face anterior dos membros inferiores. Está presente noutras entidades, não sendo específico da sarcoidose, mas constitui um indício para este diagnóstico. ${ }^{8}$

A linfadenopatia periférica está presente em 40\% dos doentes, porém a linfadenopatia mediastínica paratraqueal e hilar é visível em cerca de 90\% dos doentes com sarcoidose. ${ }^{9}$ Pode ocorrer também um envolvimento hepático e esplénico. Apesar deste doente não apresentar alterações analíticas e ao exame objetivo, a nível imagiológico já apresentava atingimento esplénico. Manifestações menos comuns são o atingimento cardíaco e neurológico que ocorre em apenas 5\% dos doentes. ${ }^{10,11}$ É necessária uma avaliação inicial com eletrocardiograma, e se necessário uma monitorização com holter e um ecocardiograma que neste doente não mostraram atingimento cardíaco. ${ }^{10}$ A neurosarcoidose pode afetar qualquer porção do sistema nervoso central ou periférico, sendo a paralisia facial periférica e a neuropatia do VIII par craniano comum, condicionando perda auditiva e disfunção vestibular tal como verificado neste caso. ${ }^{11}$

A corticoterapia em baixas doses constitui a principal arma terapêutica. Sendo, na maioria dos casos suficiente para a resolução da sintomatologia. No entanto, 10\% a 30\% dos doentes apresentam formas crónicas e progressivas da doença e necessidade diária de corticoterapia, o que obriga à introdução de outros fármacos. ${ }^{4,5}$ Neste caso clínico verificou-se melhoria e estabilização da doença com o metotrexato.

\section{CONCLUSÃO}

Este caso pretende ilustrar as várias manifestações possíveis de uma doença complexa e multissistémica que é a sarcoidose e realçar a importância do seu diagnóstico e vigilância atempada para que possamos agir na evolução e desfecho da doença.

CONFLITOS DE INTERESSE: Os autores declaram não ter qualquer conflito de interesse na realização do presente trabalho.
FONTES DE FINANCIAMENTO: Não houve qualquer fonte de financiamento na realização do presente trabalho.

CONFIDENCIALIDADE DOS DADOS: Os autores declaram ter seguido os protocolos da sua instituição acerca da publicação dos dados de doentes.

CONSENTIMENTO: Consentimento do doente para publicação obtido.

PROVENIÊNCIA E REVISÃO POR PARES: Não comissionado; revisão externa por pares.

CONFLICTS OF INTEREST: The authors declare that they have no conflicts of interest.

FINANCIAL SUPPORT: This work has not received any contribution, grant or scholarship.

CONFIDENTIALITY OF DATA: The authors declare that they have followed the protocols of their work center on the publication of data from patients.

PATIENT CONSENT: Consent for publication was obtained.

PROVENANCE AND PEER REVIEW: Not commissioned; externally peer reviewed.

\section{REFERÊNCIAS}

1. Baughman RP, Lower EE, du Bois RM. Sarcoidosis. Lancet. 2003; 361:111-8.

2. Baughman RP, Teirstein AS, Judson MA, Rossaman MD, Yeager $\mathrm{H}$, Bresnitz EA, et al. Clinical characteristics of patient in a case control study of sarcoidosis. Am J Respir Crit Care Med. 2001: 164:1885.

3. Fang $\mathrm{C}$, Huang $\mathrm{H}$, Xu Z. Immunological evidence for the role of mycobacteria in sarcoidosis: a meta-analysis. PloS One. 2016; 11:e0154716.

4. Thomas KW, Hunninghake GW. Sarcoidosis. JAMA. 2003; 289:3300-3.

5. Newman LS, Rose CS, Maier LA. Sarcoidosis. N Engl J Med. 1997; 336:1224-34.

6. Sharma OP. Fatigue and sarcoidosis. Eur Respir J. 1999; 13:713-4.

7. Baughman RP. Pulmonary Sarcoidosis. Clin Chest Med. 2004; 25:521-30.

8. Yanardag H, Pamuk ON, Karayel T. Cutaneous involvement in sarcoidosis: analysis of the features in 170 patients. Respir Med. 2003: 97:978-82.

9. Muller NL, Kullnig P, Miller RR. The CT findings of pulmonar sarcoidosis: analysis of 25 patients. ARJ AM J Roentgenol. 1989; 152:1179-82.

10. Kron J, Ellenbogen KA. Cardiac sarcoidosis: contemporary review. J Cardiovasc Electrophysiol. 2015; 26:104-9. doi: 10.1111/jce.12552.

11. Burns TM. Neurosarcoidosis. Arch Neurol. 2003; 60:1166-8. 